\title{
Study on Navigation Safety of Oilfield Water
}

\author{
Zou Yanbin \\ Wuhan University of Technology Wuhan \\ Hubei Key Laboratory of Inland River \\ Wuhan, China \\ bhzsin@163.com
}

\author{
Guo Yanbin \\ Wuhan University of Technology Wuhan \\ School of Navigation \\ Wuhan, China \\ guoyanbin@whut.edu.cn
}

\begin{abstract}
From the viewpoint of system engineering ,the navigation safety of oilfield water is analyzed and the quantitative evaluation indexes are identified. The comprehensive evaluation model is built to evaluate the navigation safety of oilfield water according to the butterfly catastrophe theory. Then the safety management measures are proposed to improve the navigation safety. This evaluation method is simple, reliable, convenient and easy. The navigation safety of oilfield water is reflected objectively on the basis of the actual statistics. It can reduce the impact of subjective factors. It provides a reliable theoretical support for the navigation safety of oilfield water, so that to protect the navigation safety of oilfield water.
\end{abstract}

Keywords- oilfield water; navigation environment; catastrophe theory; navigation safety evaluation

\section{INTRODUCTION}

In the form of marine industry, marine oil and gas development is emerging marine industry. With the development of petroleum technology, oil field operation area of existing oil and gas development has been unable to meet the demand, the development of offshore oil and gas to enter the deep waters, waters oilfields will gradually cover customary route and route the port waters, oil group waters ship traffic increased, marine traffic environment, increase the risk and consequences of complex navigation accident on water the pollution is more and more serious phenomenon, but also so much authority and social concern. Analysis and Research on Oilfield Group waters navigation safety state route has important practical significance for the realization of safe navigation route waters oilfields.

With the oilfield waters complicated traffic environment intensifies, at present, the corresponding research is mainly reflected in the drilling platform, influence on navigation safety, safety operation area of

Bohai oilfield oil platform area maritime supervision mode and the habit of oilfield route planning were studied. This article from the perspective of traffic analysis and evaluation of traffic safety in oilfields water route, puts forward suggestions for safety management, to ensure the safety of navigation route waters oilfields.

\section{TRAFFIC SAFETY EVALUATION INDEX SYSTEM}

\section{A. Oil water group}

There is no clear definition of the waters of the oil group, according to the characteristics of the existing water oil group, the group is defined as: water oil field operation
District of maritime operations, have a sufficient amount, and the formation of a certain density of production platform, operating system platform of the group has a certain scale center platform and auxiliary unified platform well, the independent operation team, long-term oil and gas development area.

\section{B. The characteristics of Oilfield Group navigable waters}

1) Intensive platform

2) The serious consequences of the accident

3) The ship sailed flexible work

4) Isolated obstacle

\section{Oilfield Group water route navigation safety} evaluation index system

\section{1) Oil water route navigation group}

a) Path smoothing:The oil platform group water intensive, ship navigation during avoidance route is more complex, but also by the ship in the process of manipulating the restriction of ships during steering, the steering angle should not be too large, requiring the ship route smoothness to meet the requirements of ship handling.

b) Exclusive area prohibited:The dangerous waters of the main oil route by route and platform of distance. The ship in navigation, try to avoid in the exclusive area.

c) Traffic:The size of the volume of traffic directly reflects the vessel traffic busy degree, have a direct impact on the probability of traffic accident on the water route of oilfields, and ship oil group in the waters of more flexible, traffic boat has a certain impact on traffic safety.

2) The evaluation index system

The use of scientific methods to establish oilfield group water route navigation safety evaluation index system, the systematic analysis of the evaluation object, by combining qualitative and quantitative methods to determine the evaluation value of single index, comprehensive evaluation of multi index. The environmental characteristics of navigable waters and waters oil oil group group requires the establishment of index system of navigation route oilfields waters sea route navigation safety evaluation based on.

Traffic safety evaluation index system of Oilfield Group waters route the existence of risk factors in the following aspects:

a) the natural risk factors, including wind, wave, flow, visibility; 
b) the navigation conditions of risk factors, including steering angle, distance, traffic platform;

c) safety risk factors, including regulatory facilities.

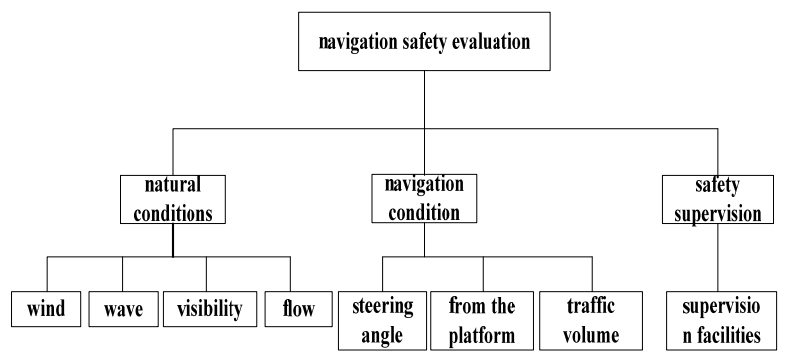

Figure 1. Oilfield Group water route navigation safety evaluation index system

\section{OILFIELD WATERS NAVIGABLE ROUTE CONSTRUCTION SAFETY EVALUATION MODEL}

\section{A. Catastrophe theory}

The French mathematician Thom was established in 1972 by the catastrophe theory of singularity theory, the stability theory of differential equation and other mathematical theory. Catastrophe theory is through potential function research object to study the mutation phenomenon. The system potential function through the system state variables $X=\left\{x_{1}, x_{2}, \ldots, x_{m}\right\}$ and external control parameters on $\mathrm{U}=\left\{\mathrm{u}_{1}, \mathrm{u}_{2}, \ldots, \mathrm{u}_{n}\right\}$, to describe the behavior of the system, namely $\mathrm{V}=f(\mathrm{U}, \mathrm{X})$. In the outside may change control parameters and the internal behavior of the collection of variables under the condition of constructing the state space and control space. By solving $V^{\prime}(x)$ and $V^{\prime \prime}(x)$, get the critical point of equilibrium system, catastrophe theory is the mutual conversion between the mutation characteristics through the study of the critical point to study system.

When the control variable is not greater than 4 , with a maximum of seven mutated forms, known as the elementary catastrophe. They are: folding mutation, cusp mutation, mutation, mutation, swallowtail butterfly hyperbolic umbilici catastrophe, elliptic umbilic catastrophe, parabolic umbilic catastrophe. $x$ and $y$ represent the state variables, $\mathrm{u} 、 \mathrm{v} 、 \mathrm{w}$ and $t$ represent the control variables, seven kinds of elementary catastrophe potential function are shown in table 1.
TABLE I. THE BASIC MUTATION TYPE TABLE

\begin{tabular}{|c|c|c|c|}
\hline type & $\begin{array}{c}\text { State } \\
\text { variable }\end{array}$ & $\begin{array}{c}\text { Control } \\
\text { variables }\end{array}$ & Potential function \\
\hline Fold & 1 & 1 & $V(x)=x^{3}+u x$ \\
\hline Cusp & 1 & 2 & $V(x)=x^{4}+u x^{2}+v x$ \\
\hline Swallowtail & 1 & 3 & $V(x)=x^{5}+u x^{3}+v x^{2}+w x$ \\
\hline Butterfly & 1 & $V($ & $x)=x^{6}+u x^{4}+v x^{3}+w x^{2}+t x$ \\
\hline Hyperbolic & 2 & $V(x$ & $x, y)=x^{3}+y^{3}+w x y+u x+v y$ \\
\hline Elliptic & \multicolumn{3}{|r|}{$V(x, y)=x^{3}-$} \\
\hline Parabolic & 2 & $V(x, y)$ & $V(x, y)=y^{4}+x^{2} y+w x^{2}+t y^{2}+u x+v y$ \\
\hline \multicolumn{4}{|c|}{$\begin{array}{c}\text { The only one control variable four eleme } \\
\text { catastrophe model was normalized by the mut } \\
\text { manifold and normalization formula, as shown in tabl } \\
\text { TABLE II. THE BASIC FORMULA OF MUTATION TYPE }\end{array}$} \\
\hline The types of $n$ & utations & Catastrophe manifold & Formula \\
\hline Fold catas & rophe & $3 x^{2}+u=0$ & $\left\{x_{u}-\sqrt{u}\right\}$ \\
\hline Cusp catas & rophe & $4 x^{3}+2 u x+v=0$ & $\left\{X_{\mathrm{u}}=\sqrt{u}, X_{\mathrm{v}}=\sqrt[3]{v}\right\}$ \\
\hline Swallowtail c & tastrophe & $5 x^{4}+3 w x^{2}+2 v x+w=0$ & $\left\{X_{\mathrm{z}}=\sqrt{u}, X_{\mathrm{v}}=\sqrt[3]{v}, X_{\mathrm{w}}=\sqrt[4]{w}\right\}$ \\
\hline Butterfly cat & istrophe & $6 x^{3}+4 w x^{3}+3 v x^{2}+2 v x+t=0$ & $\left\{X_{0}=\sqrt{u}, X_{2}=\sqrt[3]{v}, X_{w}=\sqrt[4]{w}, X_{4}=\sqrt[5]{t}\right\}$ \\
\hline
\end{tabular}

\section{B. Oil water route navigation safety evaluation model}

\section{1) butterfly catastrophe model}

The importance of natural conditions index: wind $(\mathrm{w})>$ waves (i) $>$ visibility(v) $>$ flow (f). E evaluation of Oilfield Group waters sea route of natural conditions, get butterfly catastrophe model based on:

$$
E=\left(\sqrt{W^{\prime}}+\sqrt[3]{L^{\prime}}+\sqrt[4]{V^{\prime}}+\sqrt[5]{F^{\prime}}\right) / 4
$$

2) swallowtail catastrophe model

The importance ranking navigation condition index: platform distance (d) $>$ angle (c) $>$ traffic volume (t). N evaluation of Oilfield Group waters sea route of natural conditions, are based on the swallowtail catastrophe model: $N=\left(\sqrt{D^{\prime}}+\sqrt[3]{C^{\prime}}+\sqrt[4]{T^{\prime}}\right) / 3$

For navigation safety evaluation of oilfields water route, points out three evaluation index of importance in order are: the navigation condition $(\mathrm{N})$, natural conditions (E) and safety (S). P said the safety evaluation of navigation water route oilfield group values, obtained a swallowtail catastrophe model based on:

$$
\begin{aligned}
& P=(\sqrt{N}+\sqrt[3]{E}+\sqrt[4]{S}) / 3 \\
& \text { 3) fold catastrophe model }
\end{aligned}
$$

For the safety supervision index (S), are based on fold catastrophe model:

$$
S=\sqrt{B^{\prime}}
$$




\section{The evaluation standard of risk classification}

Evaluation standard of risk rating and the score table as shown in table 3.

TABLE III. THE EVALUATION STANDARD OF DANGEROUS DEGREE CLASSIFICATION AND SCORE TABLE

\begin{tabular}{|c|c|c|c|c|c|}
\hline level & 1 & 2 & 3 & 4 & 5 \\
\hline score & $0.8-1$ & $0.6-0.8$ & $0.4-0.6$ & $0.2-0.4$ & $0-0.2$ \\
\hline \multirow{2}{*}{ nature } & 0.93297- & $0.8541-$ & $0.7557-$ & $0.61635-$ & $0-$ \\
\hline & 1 & 0.93297 & 0.8541 & 0.7557 & 0.61635 \\
\hline navigation & 0.9228-1 & $0.8327-$ & $0.7215-$ & 0.5669- & $0-$ \\
\hline condition & & 0.9228 & 0.8327 & 0.7215 & 0.5669 \\
\hline safety & $0.8944-1$ & $0.7746-$ & $0.6325-$ & $0.4472-$ & $0-$ \\
\hline supervision & & 0.8944 & 0.7746 & 0.6325 & 0.4472 \\
\hline Comprehensive & $0.9701-1$ & 0.9331- & $0.8840-$ & $0.8072-$ & $0-$ \\
\hline index score & & 0.9701 & 0.9331 & 0.8840 & 0.8072 \\
\hline
\end{tabular}

\section{The evaluation index and standard}

According to the research results at home and abroad, the theoretical basis and combining with the actual situation of domestic related research in China port setting control variablesevaluation criteria, as shown in table 4.

TABLE IV. THE CONTROL VARIABLE EVALUATION STANDARD

\begin{tabular}{cccccc}
\hline & \multicolumn{5}{c}{ Evaluation standard } \\
\cline { 2 - 6 } Control variables & 5 & 4 & 3 & 2 & 1 \\
\cline { 2 - 6 } & $\leqslant 10$ & $10 \sim 20$ & $20 \sim 30$ & $30 \sim 40$ & $>40$ \\
wind days & $\leqslant 4$ & $4 \sim 9$ & $9 \sim 15$ & $15 \sim 20$ & $>20$ \\
wave & $\leqslant 0.25$ & $0.25 \sim 0.75$ & $0.75 \sim 1.25$ & $1.25 \sim 2$ & $\geqslant 2$ \\
maximum velocity $(\mathrm{kn})$ & $\leqslant 15$ & $15 \sim 25$ & $25 \sim 40$ & $40 \sim 50$ & $>50$ \\
Poor visibility days & $\leqslant 20^{\circ}$ & $20^{\circ} \sim 40^{\circ}$ & $40^{\circ} \sim 60^{\circ}$ & $60^{\circ} \sim 80^{\circ}$ & $>80^{\circ}$ \\
Steering angle & $>2 \mathrm{~nm}$ & $3500 \mathrm{~m} \sim 2500 \mathrm{~m}$ & $2500 \mathrm{~m} \sim 1500 \mathrm{~m}$ & $1500 \mathrm{~m} \sim 500 \mathrm{~m}$ & $\leqslant 500 \mathrm{~m}$ \\
From the platform & $\leqslant 10$ & $10 \sim 30$ & $30 \sim 50$ & $50 \sim 70$ & $\geqslant 70$ \\
flow(s/d) & $>5$ & $4 \sim 5$ & $3 \sim 4$ & $2 \sim 3$ & $\leqslant 2$ \\
Types of safety facilities & & & & &
\end{tabular}

Standardization of evaluation indicators by means of processing the evaluation index values, with values between $0-1$ said evaluation index. Oilfield Group route navigation facilities from the platform, the waters of supervision in safety evaluation for positive indicators, namely the larger oil group better route navigation waters; wind, wave, flow, visibility, steering angle, traffic volume for the reverse indicator, its value is small, the better state route navigation waters oilfields. According to the evaluation standard should follow the same index of internal relative gap gap between different indexes, the principle of invariant relativity between the uncertainty principle and the normalized maximum value equal to the principle of three principles, as well as the actual navigable waters oilfields and sea condition indexes standardization.

\section{ANALYSIS OF SAFETY EVALUATION OF NAVIGATION IN CHENGDAO OILFIELD GROUP WATER ROUTE}

\section{A. The evaluation process and results}

This paper selects the Huanghua Changshan channel used navigation in Chengdao oil field waters by center, a section of route as an example, the navigation safety evaluated. Statistical data obtained in Chengdao oil field waters navigable data related to the environment and the natural environment, according to the linear interpolation method for navigation safety factor index value, and using the formula (1), (2) and (4) of secondary state variables were evaluated, finally (3) to a level control variables were evaluated according to the formula, evaluation results are shown in Table 5 shows.

TABLE V. TRAFFIC SAFETY EVALUATION INDEX VALUE AND STANDARDIZATION VALUE

\begin{tabular}{ccccccccc}
\hline factors & $W^{\prime}$ & $L^{\prime}$ & $F^{\prime}$ & $V^{\prime}$ & $C^{\prime}$ & $D^{\prime}$ & $T^{\prime}$ & $B^{\prime}$ \\
\hline Statistical value & 10 & 6 & 0.25 & 15 & $22^{\circ}$ & $2000 \mathrm{~m}$ & 11 & 3 \\
Standard value & 0.20 & 0.28 & 0.20 & 0.20 & 0.22 & 0.50 & 0.21 & 0.60 \\
Index factor & & nature $(E)$ & & conditions $(N)$ & safety $(S)$ \\
Standard value & \multicolumn{1}{c}{0.6337} & & & 0.6626 & & 0.7746 \\
Comprehenaive & & & & 0.8703 & & & \\
evaluation value & & & & & & &
\end{tabular}

B. The evaluation results of analysis

According to the evaluation criteria of dangerous degree classification of known, Chengdao oil field waters en route navigation safety state at a low risk level, the results are as shown in Figure 2.

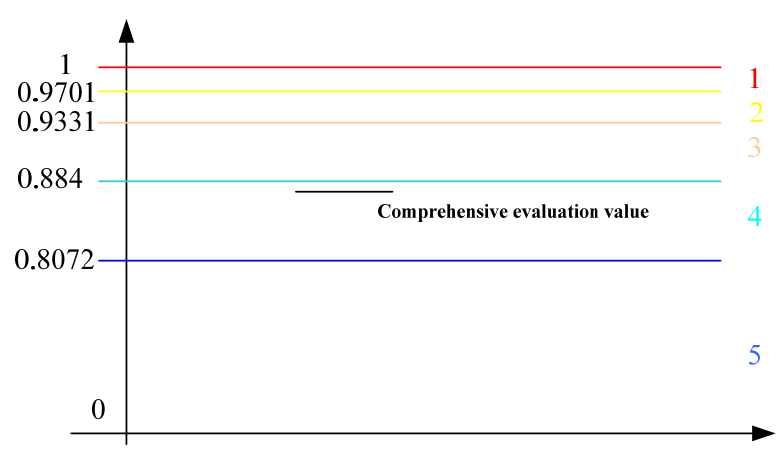

Figure 2. Chengdao Oilfield Group water route navigation safety evaluation results

From the establishment of evaluation system and the evaluation indexes for the standardized value and evaluation results, Chengdao oil field waters en route navigation the safe state at a low risk rating, but poor safety conditions of supervision in moderate risk level, according to the details, Chengdao oil field waters should be as soon as possible, perfect supervision system infrastructure construction, to ensure Oilfield Group waters navigation safety. 


\section{CONCLUSION}

The catastrophe theory construction of oilfield waters en route navigation safety evaluation model based on, via intuitive quantitative expression of oilfield waters en route to the navigation safety state, and put forward the corresponding proposal and the evaluation method and evaluation system can be for oil field waters en route navigation safety comprehensive evaluation to provide the reference.

\section{REFERENCES}

[1] Shen Chongsong, "Study on safety operation area of offshore platforms in the Bohai sea area," Tianjin navigation, vol. 3,Dec. 2010,pp.28-29.

[2] KyuMan C,TaeHoon H and ChangTaek H, "Effect of Project Characteristics on Project Performance in Construction Projects Based on Structural Equation Model," Expert Systems With Applications . 2009

[3] Sun Haitao and Li Changwei, "Influence on navigation safety of offshore platform and the Countermeasures," China waterway, vol. 9, 2009, pp. 30-31.
[4] Li Kaibao and Zhou Zhentao, "Discussion on Bohai oilfield area maritime supervision mode,” Tianjin navigation, vol. 2,Oct. 2012,pp.16-17.

[5] Ma Quandang, "Rearch on Typical Waters Ship Route Dynamic Planning Model and its Application," Wuhan University of Technology Wuhan,2012.

[6] Yuanyuan Ren, Xiansheng Li, Lidong Tan and Shuxia Zuo. Research on Road Traffic System Safety Evaluation Based on Catastrophe Control Model [A]. 2010 International Conference on Intelligent Computation Technology and Automation, pp96-99.

[7] Henry O. Pruden. Catastrophe theory and technical analysis applied to a Cal Tech experiment on irrational exuberance[J]. Managerial Finance,2005,315.

[8] Yu Deng,Lin-Lin Jiang,Chao Wang,Fu-Quan Ni. Research on the Risk Associated with Rural Drinking Water Safety Based on Catastrophe Theory[J]. Journal of Water Resource and Protection,2011,0306.

[9] Guarini G. The application of the theory of systems in internal medicine. State of the art and perspectives.[J]. Annali italiani di medicina interna : organo ufficiale della Società italiana di medicina interna,1991,61 pp 2.

[10] G. P. Pelyukh. On the theory of systems of linear difference equations with a continuous argument[J]. Doklady Mathematics,2006,732.

[11] Jing-Xian LIU, Zhao Liu and Ying Chen. Evaluation of Navigation Status of the Three Gorges Ship Lock Based on Butterfly Catastrophe Theory. Proceedings of Asia Navigation Conference2011,2011,pp.477-485. 